\title{
Evaluating psychometric properties of the Short Form Brief Pain Inventory Sinhala Version (SF BPI-Sin) among Sinhala speaking patients with cancer pain in Sri Lanka
}

\author{
Nirosha Priyadarshani Edirisinghe ${ }^{1}$ (D), Thamasi Rekha Makuloluwa ${ }^{2}$ (B), Thamara Dilhani Amarasekara ${ }^{3}$ (1) \\ and Christine Sampatha Evangeline Goonewardena ${ }^{4,5^{*}}$ (i)
}

\begin{abstract}
Background: Pain is one of the most common and unpleasant symptoms of patients with cancer. The Short Form Brief Pain Inventory (SF-BPI), has been psychometrically validated in several languages and widely used globally. Availability of a validated pain tool in Sinhala is a current requirement enabling the use among the majority of Sinhalaspeaking cancer patients in Sri Lanka. The purpose of the study was to evaluate the psychometric properties of Sinhala translated version of SF BPI.

Methods: The translation was done by forward-backward translation method. Content and face validity were evaluated by a panel of experts and patients with cancer pain respectively. The study included 151 participants with cancer pain, registered at the Pain Clinic, Apeksha Hospital, Sri Lanka. The reliability, discriminant and convergent validity were assessed. The confirmatory factor analysis (CFA) was conducted and evaluated the two factor (severity, interference) and three factor models (severity, affective/ activity interference). In the three factor model-1, item 'sleep' was included within the affective interference along with mood, relationship with others and enjoyment of life. In the three factor model-2, item 'sleep' was included within the activity interference along with general activities, walking and normal works. Ethical approval was obtained from the Ethics Review Committee, Faculty of Medical Sciences, University of Sri Jayewardenepura, Sri Lanka.
\end{abstract}

Results: A total of 151 participants (79 males, 72 females) with a mean age of $54.6(+/-13.2)$ years were included. The composite reliability $(0.902,0.879)$, average variance extracted (AVE) $(0.647,0.568)$ and Cronbach's alpha (0.819, 0.869) calculated for each severity and interference subscales were acceptable. The discriminant validity assessed with the heterotrait-monotrait criterion was 0.18. According to the Fornell-Larcker criterion, the square root of AVE of severity and interference factors $(0.804,0.753)$ greater than the correlation between the factors $(0.140)$ demonstrated the discriminant validity. The CFA supported the three-factor model-2 (CFI—0.959, SRMR—0.0513, RMSEA—0.0699) and the values for two-factor and three-factor model-1 were marginally acceptable.

Conclusions: The Sinhala version of SF BPI is a reliable and valid instrument for the assessment of cancer pain among Sinhala speaking patients in Sri Lanka.

\footnotetext{
*Correspondence: sampatha@sjp.ac.lk

${ }^{4}$ Department of Community Medicine, Faculty of Medical Sciences,

University of Sri Jayewardenepura, Gangodawila, Nugegoda, Sri Lanka

Full list of author information is available at the end of the article
}

(C) The Author(s) 2021. Open Access This article is licensed under a Creative Commons Attribution 4.0 International License, which permits use, sharing, adaptation, distribution and reproduction in any medium or format, as long as you give appropriate credit to the original author(s) and the source, provide a link to the Creative Commons licence, and indicate if changes were made. The images or other third party material in this article are included in the article's Creative Commons licence, unless indicated otherwise in a credit line to the material. If material is not included in the article's Creative Commons licence and your intended use is not permitted by statutory regulation or exceeds the permitted use, you will need to obtain permission directly from the copyright holder. To view a copy of this licence, visit http://creativecommons.org/licenses/by/4.0/. The Creative Commons Public Domain Dedication waiver (http://creativeco mmons.org/publicdomain/zero/1.0/) applies to the data made available in this article, unless otherwise stated in a credit line to the data. 
Keywords: SF BPI-sin, Cancer pain, Pain assessment, Reliability, Validity

\section{Background}

Pain is a frequent and overwhelming symptom that diminishes the quality of life of patients with cancer [1]. More than one out of four patients with early-stage cancer experience cancer-related pain, and according to recent statistics, approximately three out of every four patients with advanced disease suffer from pain [2, 3]. Further, Oliver et al. [4] state that unrelieved pain has a significant impact on a patient's physical, psychological, social and spiritual well-being. Studies have reported that despite the existing guidelines and new treatment modalities, a significant proportion of patients worldwide do not have satisfactory control over their cancer pain [1].

Cancer pain is complex, which varies individually in response to the associated bio-psycho-social- spiritual interactions [5]. Pain experienced in turn has a variable influence on the well-being of the individual [6]. Caraceni highlights the importance of in-depth assessment and evaluation of cancer pain as the first steps in managing cancer pain effectively [7]. Melzack and Casey suggested a three dimensional model of pain assessment comprising of sensory-discriminative, motivational-affective, and cognitive-evaluative, based on neurophysiological mechanisms of pain [8]. Therefore, the assessment of cancer pain favours the use of multidimensional scales to evaluate the overall interference of pain on the individual, apart from its severity.

The National Cancer Institute (NCI) and the Cancer Unit of World Health Organization (WHO) favour measurement tools capable of detecting the severity and impact of cancer pain and outcomes following pain interventions [9]. Among several multidimensional pain assessment tools available for the measurement of cancer-related pain in clinical and research settings [10], the short form Brief Pain Inventory (SF BPI) and McGill Pain Questionnaire are tools used globally. Under the direction of the Pain Research Group, headed by Charles S. Cleeland, the Cancer Unit of the World Health Organization (WHO) has developed the extended version of the Brief Pain Inventory in 1984 to obtain estimates of pain prevalence and, to measure the severity of pain and its interference with the function. However, currently the short version of BPI (SF BPI) is used widely as it is short, easily understood and administered to a large number of patients $[11,12]$. Many studies have used SF BPI as the most beneficial multidimensional tool for the assessment of pain and its interference on patients with cancer $[13,14]$. SF BPI has been recommended as a core measure by the Initiative on Methods, Measurement, and Pain Assessment in Clinical Trials (IMMPACT) [15] and Expert Working Group of the European Association of Palliative Care [7]. The SF BPI has been translated and validated into many different languages, and it has shown consistent measurement characteristics across different languages and various cultural groups [16-22]. Therefore, SF BPI has been used in multinational studies of cancer epidemiology, analgesic clinical trials, and the assessment and treatment of cancer pain. Additionally, the SF BPI has been used to derive the Pain Management Index, which is used to evaluate the adequacy of cancer pain management by comparing the intensity of pain to the standard guidelines for prescribing analgesics [23].

One of the first studies of the BPI compared the factor structure of four language versions of the BPI used to assess cancer pain in the United States, Mexico, the Philippines, and Vietnam [24]. For each language version, two factors emerged with an eigenvalue greater than one. The first factor consisted of the pain interference items and the second factor, the pain severity items. This twofactor structure was confirmed in a large national study conducted in the U.S. by the Eastern Cooperative Oncology Group [25]. Further, the study by Cleeland et al. demonstrated activity and affective subscales of the interference items using multidimensional scaling [26]. In terms of reliability, Cronbach's alpha showed good internal consistency, ranging from 0.80 to 0.87 for the four pain severity items and, from 0.89 to 0.92 for the seven interference items by the study of Cleeland et al. [25].

In Sri Lanka, the problem of cancer is so fast-growing that it has become an essential public health concern. The Annual Health Bulletin, 2015 [27] has reported that neoplasms are ranked as the second leading cause of death in Sri Lanka since 2010. Most of these patients have advanced disease at diagnosis, putting them at much higher risk for pain and other symptoms than those with earlier-stage of disease. The number of patients suffering from cancer pain is increasing day by day, with the frequent readmissions due to unrelieved pain, with considerable impact on health care costs of the country. Among the previous cancer pain-related studies conducted in Sri Lanka, none have used multidimensional pain scales to assess the overall impact of the cancer pain on the patients. Except for the validated Sinhala version of Short-form McGill Pain Questionaire-2, which mainly measures the qualities of pain [28], no other Sinhala versions of validated multidimensional instrument is currently available to assess cancer pain in Sri Lanka. 'Sinhala', being the native language of the majority of 
the Sri Lankan population, the availability of validated pain scales in the Sinhala language therefore immensely supports the facilitation of the assessment of pain and its interference on functions among Sinhala speaking patients with cancer. The Sinhala version of SF-BPI (SF BPI-Sin) meets these requirements.

This study was conducted to translate, culturally adapt, and validate the SF BPI, enabling the assessment of pain severity and interference among Sinhala speaking patients with cancer pain. The psychometric properties of SF BPI-Sin in terms of face, content, consensual validity, construct validity and reliability were evaluated.

\section{Methods}

\section{Study design and setting of the study}

The validation study includes translation, cultural adaptation, and evaluation of psychometric properties. The translation was carried out using the widely accepted forward-backward translation method, and in consultation with the clinical and subject experts in the field of pain medicine. A cross-sectional study was conducted to evaluate the psychometric properties among Sinhala speaking patients with cancer pain, registered at the Pain Clinic of Apeksha Hospital, Maharagama, Sri Lanka.

\section{The procedure of translation of SF BPI English version to Sinhala version}

The translation process was conducted according to the guidelines provided by the MD Anderson Cancer Center, USA. The translation process consists of 5 steps: forward translation, back translation, review by experts, cognitive debriefing, and proofreading. Two sets of forward translations in-to Sinhalese language, back translations into English, expert opinions, and cognitive debriefings were carried out separately. Two preliminary Sinhala versions were evaluated and a harmonized Sinhala version was prepared. The forward translated harmonized version was then back-translated by two independent translators who speak both Sinhala and English languages fluently. For the items or response choices where back-translations and original versions did not match, the choice of words was discussed among the translators until a final version was reconciled under the guidance of the original authors. Content validity was checked by obtaining expert opinion. Experts who were invited comprised of Consultant Anesthetists specialized in pain medicine and senior academics in nursing, Consultant Community Physicians and nurses in charge of pain clinics. The expert panel assessed the content, the appropriateness of the words used and their cultural relevance and the translation equivalence of each item. The resulting version was used in cognitive debriefings of 15 patients with cancer pain to evaluate the face validity. Participants were chosen purposively (Heterogeneous Sampling) by looking at subjects from all available angles to ensure selection of a diverse group of patients across a broad spectrum of socio-demographic characteristics, representing different provinces in the country with different types of cancers. The interviews were directed towards each item in the questionnaire separately, in order to determine if the word flow in the questions has made any of the items difficult to understand, confusing, difficult to answer and objectionable. It was also examined whether the questions could have been asked in a different way to improve comprehensibility. Based on the comments of the participants, minor changes were made to the document as a collective decision of the research team, without affecting the meaning of the items. Face validity testing needed no further major revisions in respect of the item content or scoring. Proofreading was carried out to eliminate any grammatical, spelling, typographical and/or formatting errors.

\section{Sample and sample size calculation}

The study included all patients above the age of 18 years diagnosed with any type of cancer, with a pain score $>1$ on Numerical Rating Scale, with pain related to primary lesion, secondaries, radiotherapy, or chemotherapy, and whose pain lasted at least for three months or more since the diagnosis of cancer. Irrespective of ethnicity, all patients capable of speaking and comprehending Sinhala language were included in the study. Patients whose pain is due to any cause other than cancer, or pains that lasted less than three months from the time of assessment, or who are too frail or mentally unfit or unwilling to give informed consent were excluded from the study.

The sample size was calculated considering the rule of thumb of 5-10 subjects per item [29]. There were 15 items in the instrument and the calculated sample size was 150 , considering 10:1 subject to the variable ratio. Five percent was added considering non response rate; therefore, the final calculated sample size was 158. Participants fulfilling the selection criteria were recruited for the validation study by consecutive sampling method until the sample size was reached.

Out of all the data sheets received, five were incomplete and two were noted as outliers. Therefore, data from 151 participants were included for analysis (response rate-95.5\%). The mean age of the participants was 54.6 $(+/-13.2)$, and the age range varied from 20 to 80 years. The majority, $52.3 \%$ were males $(n=79)$ and $47.7 \%$ were females $(\mathrm{n}=72)$. Among the participants, majority $(25.2 \%)$ were diagnosed with uro-genital cancers $(n=38)$ followed by gastro-intestinal $(\mathrm{n}=36,23.8 \%)$ and orofacial $(n=31,20.5 \%)$. The mean duration of pain, since its 
onset, was $8.14(+/-10.5)$ months. Table 1 depicts the socio-demographic characteristics of the sample.

\section{Measurements}

SF-BPI-Sinhala is a self-administered or intervieweradministered pain rating scale with four questions related to pain intensity, with responses rated on a numerical rating scale ranging from 0 to 10 ; " 0 " is "no pain" and " 10 " is "pain as bad (excruciating) as you can imagine". Cancer patients rate their worst, least and average pain in the last $24 \mathrm{~h}$ and, the pain experienced at the time they were responding to the questionnaire. Pain interference on general activity, mood, walking ability, normal work, relationships with other people, sleep and enjoyment of life were rated on a numerical scale from $0=$ "Does not

Table 1 Socio-demographic characteristics $(n=151)$

\begin{tabular}{|c|c|c|}
\hline & Frequency & Percentage \\
\hline \multicolumn{3}{|l|}{ Age } \\
\hline \multicolumn{3}{|c|}{ Mean 54.6 (SD \pm 13.2) Range 20-80 } \\
\hline \multicolumn{3}{|c|}{ Gender } \\
\hline Male & 79 & 52.3 \\
\hline Female & 72 & 47.7 \\
\hline \multicolumn{3}{|l|}{ Race } \\
\hline Sinhala & 133 & 88 \\
\hline Tamil & 10 & 6.6 \\
\hline Muslim & 3 & 2 \\
\hline Burger & 4 & 2.6 \\
\hline Malay & 1 & 0.7 \\
\hline \multicolumn{3}{|l|}{ Level of education } \\
\hline Not attended to school & 11 & 7.2 \\
\hline Up to grade 5 & 54 & 35.7 \\
\hline Up to grade 11 & 50 & 33.1 \\
\hline Up to grade 13 & 33 & 21.9 \\
\hline Graduate & 2 & 1.3 \\
\hline Post graduate & 1 & 0.7 \\
\hline \multicolumn{3}{|l|}{ Marital status } \\
\hline Single & 13 & 8.6 \\
\hline Married & 111 & 73.5 \\
\hline Divorced & 4 & 2.6 \\
\hline Living together & 1 & 0.7 \\
\hline Widow & 22 & 14.6 \\
\hline \multicolumn{3}{|l|}{ Cancer diagnosis } \\
\hline Uro-genital & 38 & 25.2 \\
\hline Gastro-intestinal & 36 & 23.8 \\
\hline Oro-facial & 31 & 20.5 \\
\hline Other & 17 & 11.3 \\
\hline Lung & 14 & 9.3 \\
\hline Breast & 9 & 6 \\
\hline Blood & 6 & 4 \\
\hline
\end{tabular}

interfere" to $10=$ "Interferes completely". The scale comprised of a diagram of a human figure for locating areas of pain and, questions about pain medications and the percentages of pain relief achieved with medications in the last $24 \mathrm{~h}$.

\section{Procedure of data collection}

The data were collected between November 2017 and May 2018. Those who expressed interest in participating in fulfilling the inclusion criteria were invited to read and sign a consent form. After obtaining the informed written consent, data were collected from the participants of the validation study using an interviewer-administered SF-BPI-Sin questionnaire uniformly by the principal investigator. Additionally, the information regarding the demographic characteristics, type of cancer, duration of pain since the diagnosis of cancer, other comorbidities, and the details of the previous and current treatment interventions were noted.

\section{Analysis}

Statistical analysis was conducted using IBM SPSS Statistics version 20.0 for windows [30]. Internal consistency was assessed using composite reliability (CR), (range from 0.70 to 0.90) [31] and Cronbach's alpha coefficients $(\geq 0.70)$ as reliability measures [32]. Construct validity was evaluated using convergent and divergent validity and confirmatory factor analysis (CFA). The measurement model was assessed using the average variance extracted (AVE) $(>0.5)$ and the composite reliability $(\mathrm{CR})$. Discriminant validity was examined by Fornell Larcker Criterion; in which the square root of each construct's AVE should have a greater value than the correlations with other latent constructs [33] and heterotrait-monotrait (HTMT) criterion $(<0.9)$ [34]. After ensuring the reliability and validity, CFA of the construct measures was performed using Lisrel 10.20 for windows [35], with the following fit indices. Chi-square value (low-value) and the associated degrees of freedom, Comparative Fit Index $(\mathrm{CFI})>0.95$, Standardized Root Mean Square Residual (SRMR) $<0.08$ and Root Mean Square Error of Approximation (RMSEA) $<0.06$ [36]. We hypothesized the original two-factor model (severity, interference) and three-factor model-1, as found in the factor models in the literature (severity, activity interference-own general activities, walking, normal works and affective interference- mood, relationship with others, enjoyment of life, sleep), and three-factor model- 2 as alternatively proposed by the original test authors (severity, activity interference-own general activities, walking, normal works, sleep and affective interference-mood, relationship with others, enjoyment of life). 


\section{Ethical considerations}

The study was approved by the Ethics Review Committee (ERC No: 32/17) of the Faculty of Medical Sciences, University of Sri Jayewardenepura, Sri Lanka. Informed written consent was obtained from the study participants before the collection of data. Administrative permission for data collection was obtained from the Director, Apeksha Hospital Maharagama, Sri Lanka.

\section{Results}

Prior to performing analysis, the data set was assessed for quality, suitability, and any missing data or violations of the assumptions demanded by the analytical techniques in CFA. Respondents with two or more missing items were excluded from the analysis. Continuous variables were descriptively summarized using means and standard deviations. Standardized values (Z-scores) \pm 3 were assessed to identify the univariate outliers of each item. Two outliers were identified with a Z-score of 3.4. The raw data set was checked for errors in data entry. In the absence of errors and major deviations in the data set, no adjustments were made. Data were assessed for multivariate outliers using Mahalanobis Distance and, two were detected and removed. The normalcy of data assessed using histograms and Q-Q plots showed several items with non-normal distributions. Both the KolmogorovSmirnov test and the Shapiro-Wilk's tests were significant $(\mathrm{p}<0.05)$, indicating that the data were not normally distributed. Standardized skewness and kurtosis values were calculated; seven and five items out of 11 items had exceeding \pm 3 values indicating high skewness and kurtosis respectively. The sampling adequacy was assessed using the Kaiser-Meyer-Olkin measure of sampling adequacy (desirable value $>0.8$ ) 0.816 and Bartlett's test of sphericity was noted to be significant [37].
Descriptive analysis of the SF BPI-Sin

Among the study participants, worst, least, average and current pain had mean values (SD) of 8.06 (1.79), 1.11 (1.37), 4.75 (1.54) and 3.87 (1.81) respectively. Concerning the interference, pain interfered mostly with the enjoyment of life with mean values (SD) 7.87 (2.13), mood 7.70 (2.21), normal works 6.93 (2.46), and sleep 6.17 (2.62). The least interference was observed on relationships with others with a mean of 4.58 (2.34) as illustrated in Table 2.

\section{Psychometric properties}

Assessment of the reliability was conducted by CR and Chronbach's alpha. The CR was 0.902 and 0.879 and, the Chronbach's alpha values were found to be 0.819 and 0.868 for severity and interference subscales respectively. Further, Cronbach's alpha could be increased by 0.020 , if item 'least pain' deleted, as mentioned in Table 3.

The AVE values used to assess convergent validity of severity and interference subscales were 0.647 and 0.568 as shown in Table 4 . Discriminant validity was examined according to the Fornell-Larcker criterion which shows the square root of AVE for severity and interference subscales as 0.80 and 0.753 respectively. According to the component correlation matrix, the correlation between the factors was 0.140 . Discriminant validity assessed by HTMT was 0.18 , which is lower than the threshold, and which enabled concluding the discriminant validity of SF BPI-Sin. Item-to-total correlations were measured to test how well each item score correlates with the overall SF BPI - Sin score. The item-to-total correlations were above the acceptable level $>0.50$ [31] except for 'least pain' (0.477). All the inter-item correlations were observed to be within the acceptable range ( 0.30 to 0.80$)$ [31]; from 0.330 to 0.697 .

Table 2 Descriptive statistics of SF BPI-Sin scores $(n=151)$

\begin{tabular}{|c|c|c|c|c|c|c|}
\hline BPI Item & Mean & SD & Minimum & Maximum & Skewness & Kurtosis \\
\hline Worst pain & 8.06 & 1.79 & 3 & 10 & -0.522 & -0.780 \\
\hline Least pain & 1.11 & 1.37 & 0 & 6 & 1.233 & 1.245 \\
\hline Average pain & 4.75 & 1.54 & 1 & 8 & -0.168 & -0.410 \\
\hline Pain now & 3.87 & 1.81 & 0 & 8 & -0.330 & -0.351 \\
\hline General activity & 5.59 & 2.57 & 0 & 10 & -0.507 & -0.545 \\
\hline Walking ability & 5.23 & 3.24 & 0 & 10 & -0.320 & -1.293 \\
\hline Normal works & 6.93 & 2.46 & 0 & 10 & -1.122 & 0.698 \\
\hline Sleep & 6.17 & 2.62 & 0 & 10 & -1.115 & 0.582 \\
\hline Relationships & 4.58 & 2.34 & 0 & 10 & 0.295 & -0.527 \\
\hline Enjoyment of life & 7.87 & 2.13 & 0 & 10 & -1.813 & 4.060 \\
\hline Mood & 7.70 & 2.21 & 0 & 10 & -1.693 & 2.993 \\
\hline
\end{tabular}


Table 3 Comparison of internal consistency among subscales $(n=151)$

\begin{tabular}{|c|c|c|c|c|c|c|}
\hline \multirow[t]{3}{*}{ BPI Items } & \multicolumn{6}{|c|}{ Cronbach's alpha } \\
\hline & \multicolumn{2}{|l|}{ Two factors } & \multicolumn{2}{|c|}{ Three factor 1} & \multicolumn{2}{|c|}{ Three factor 2} \\
\hline & $\begin{array}{l}\text { Item total } \\
\text { correlation }\end{array}$ & $\begin{array}{l}\text { Alpha if item } \\
\text { deleted }\end{array}$ & $\begin{array}{l}\text { Item total } \\
\text { correlation }\end{array}$ & $\begin{array}{l}\text { Alpha if item } \\
\text { deleted }\end{array}$ & $\begin{array}{l}\text { Item total } \\
\text { correlation }\end{array}$ & $\begin{array}{l}\text { Alpha } \\
\text { if item } \\
\text { deleted }\end{array}$ \\
\hline & \multicolumn{2}{|c|}{ Severity (alpha = 0.819) } & \multicolumn{2}{|c|}{ Severity (alpha = 0.819) } & \multicolumn{2}{|c|}{ Severity (alpha =0.819) } \\
\hline Worst pain & 0.637 & 0.776 & 0.637 & 0.776 & 0.637 & 0.776 \\
\hline Least pain & 0.477 & 0.839 & 0.477 & 0.839 & 0.477 & 0.839 \\
\hline Average pain & 0.781 & 0.710 & 0.781 & 0.710 & 0.781 & 0.710 \\
\hline \multirow[t]{2}{*}{ Pain now } & 0.698 & 0.745 & 0.698 & 0.745 & 0.698 & 0.745 \\
\hline & \multicolumn{2}{|c|}{ Interference (alpha $=0.868$ ) } & \multicolumn{2}{|c|}{ Activity (alpha $=0.829$ ) } & \multicolumn{2}{|c|}{ Activity (alpha $=0.813$ ) } \\
\hline General activity & 0.664 & 0.847 & 0.644 & 0.803 & 0.645 & 0.760 \\
\hline Walking ability & 0.631 & 0.857 & 0.669 & 0.806 & 0.659 & 0.759 \\
\hline \multirow[t]{2}{*}{ Normal works } & 0.796 & 0.829 & 0.784 & 0.683 & 0.777 & 0.704 \\
\hline & & & \multicolumn{2}{|c|}{ Affective (alpha =0.789) } & & \\
\hline \multirow[t]{2}{*}{ Sleep } & 0.571 & 0.859 & 0.567 & 0.759 & 0.487 & 0.828 \\
\hline & & & & & \multicolumn{2}{|c|}{ Affective (alpha $=0.759$ ) } \\
\hline Relationships with others & 0.534 & 0.863 & 0.476 & 0.796 & 0.492 & 0.790 \\
\hline Enjoyment of life & 0.680 & 0.847 & 0.713 & 0.685 & 0.665 & 0.593 \\
\hline Mood & 0.691 & 0.845 & 0.664 & 0.706 & 0.621 & 0.640 \\
\hline
\end{tabular}

The items which increase the alpha values 'if deleted', more than the subscale values were indicated with bold numerals

Table 4 Composite reliability (CR), the square root of the Average Variance Extracted (AVE) (in bold) and correlations between constructs (off-diagonal)

\begin{tabular}{llll}
\hline Latent constructs & Composite reliability & Average variance extracted & $\begin{array}{l}\text { Latent constructs } \\
\text { Severity subscale }\end{array}$ \\
\hline $\begin{array}{l}\text { Severity subscale } \\
\text { Interference subscale }\end{array}$ & 0.902 & 0.647 & $\mathbf{0 . 8 0 4}$ \\
subscale & 0.140 \\
\hline
\end{tabular}

CFA was performed for the SF BPI items, after ensuring that the required assumptions had been met. The robust maximum likelihood method was adjusted for the non-normality of the data, as recommended by LISREL software, to estimate the model parameters [38]. The 3 factor model-2 came up with better model fit indices according to the combinational rule by $\mathrm{Hu}$ and Bentler, [36] and recommendations by Jackson et al. [39] as shown in Table 5. Accordingly, authors used Chi-squared value of $71.24(\mathrm{df}=41)(\mathrm{p}<0.000)$, CFI (0.959) in combination with SRMR (0.0513) and RMSEA $=0.0699$ to evaluate the model fit. The other fit indices considered were as follows; GFI $=0.922$, $\mathrm{AGFI}=0.874 \quad \mathrm{NNFI}=0.944, \quad \mathrm{PGFI}=0.573 \quad$ and $\mathrm{PNFI}=0.678[36,38-40]$.

\section{Discussion}

The SF BPI, is one of the most widely used multidimensional pain scales, with items for pain severity assessment and for measuring pain interference. The main objective of the present study was to determine the validity and reliability of the translated pain tool, SF BPI-Sin. The SF BPI questionnaire itself is short and simple and it consists of a relatively minimal number of descriptive words that have been translated and validated in several languages. The conceptual equivalence between the original and the Sinhalese version of the SF BPI was well maintained through the approach of forward and backward translation. Content validity was confirmed as acceptable by the experts in the field of pain, and the face validity was confirmed by the patients. Further, it was demonstrated to 
Table 5 Fit Indices for Confirmatory Factor Models of the sample $(n=151)$

\begin{tabular}{lllll}
\hline Indices & Reference values & 2 Factor model & 3 Factor model-1 & 3 Factor model- 2 \\
\hline Chi-square & & 91.53 & 86.86 & 71.24 \\
Df & & 43 & 41 & 41 \\
P & $<0.08$ & $<0.05$ & $<0.05$ & $<0.05$ \\
SRMR & $>0.95$ & 0.0594 & 0.0544 & 0.0513 \\
CFI & $<0.06$ & 0.933 & 0.946 & 0.959 \\
RMSEA & & 0.0864 & 0.0861 & 0.0699 \\
(90\%Cl) & $>0.9$ & $0.0618 ; 0.111)$ & $(0.0608 ; 0.111)$ & $(0.0415 ; 0.0965)$ \\
GFI & $>0.9$ & 0.898 & 0.911 & 0.922 \\
AGFI & $>0.95$ & 0.844 & 0.857 & 0.874 \\
NNFI & $>0.5$ & 0.915 & 0.928 & 0.944 \\
PGFI & $>0.5$ & 0.585 & 0.566 & 0.573 \\
PNFI & 0.691 & 0.674 & 0.678
\end{tabular}

RMSEA Root Mean Square Error of Approximation, GFI Goodness of Fit Index, AGFI Adjusted Goodness of Fit Index, SRMR Standardized Root Mean Square Residual, CFI Comparative Fit Index, NNFI Non-Normed Fit Index, PGFI Parsimony Goodness of Fit Index, PNF Parsimonious Normed Fit Index

be a convenient and user-friendly tool. Apeksha Hospital Maharagama, the premier treatment center for patients with cancers in Sri Lanka, was chosen as the study setting for sampling, due to the ethno-geographic and cultural diversity of its patients. The results of this study can be generalized to a wider population of patients experiencing cancer pain in Sri Lanka.

The current study has demonstrated the psychometric properties of the SF BPI-Sin, and hence, it can be used as a valid and reliable tool that measure of cancer pain and its interference on the functions of Sinhala speaking patients during the clinical practice and in a research setting. Pain outcome measures such as 'pain worst' and 'pain average' would be useful in evaluating the response to pain interventions used in the preceding $24 \mathrm{~h}$. The mean value of the SF BPI-Sin's interference items would be a useful overall measure of the impact of pain on functions.

Several studies conducted on the psychometric properties of the SF BPI, translated and validated in different languages, have shown SF BPI as a valid and reliable scale to assess the pain of patients with cancers [17, 22, 41]. Apart from the two factor model, the three-factor model was also validated among patients with cancers and other chronic pain conditions [42].

The reliability was assessed by internal consistency; with CR, and Cronbach's alpha. All the CR values were within the acceptable range, and alpha coefficients were above the acceptable threshold of 0.7 . The CR is the upper bound for internal consistency and it was identified to be strong in this study, demonstrating acceptable internal consistency of the scales. Although there is a slight increase in 'if item deleted', Cronbach's alpha values for 'least pain', authors and experts in the field decided to retain all the items in the instrument, considering its strong CR and having considered its worthiness in pain assessment. However, the results demonstrated reasonably high levels of internal consistency and CR even without removing the item. The study conducted by Zeng [43] has shown the psychometric validity and reliability with the three-factor model, after removing 'least pain' and 'sleep' items. Nevertheless, ten out of eleven corrected item-total correlations were more than 0.5 , indicating that no item should be revised or excluded [44]. The inter-item correlations and corrected item-total correlations of this study further support the acceptable reliability of SF BPI-Sin.

The construct validity of the scale was assessed by convergent validity, divergent validity and CFA. Convergent validity was assessed by AVE and CR. The AVE calculated for each construct was above the acceptable level of 0.5 for the two-factor model, and CR was within the acceptable range. The discriminant validity assessed with Fornell-Larcker criterion; which was commonly used to assess the degree of shared variance between the latent variables of the model. The square root of AVE of each two constructs was greater than the correlation involving the constructs that demonstrate acceptable discriminant validity. Further, the discriminated validity was assessed by a new and more stringent method of HTMT criterion, and it demonstrated acceptable discriminating ability of two constructs.

Authors have evaluated the construct validity of the tool with CFA, for originally hypothesized two-factor model, alternatively suggested, three-factor model-1 and three-factor model-2. The best combinational rule fit indices of CFI and SRMR were used for minimizing error rates due to the small $(<250)$ sample size of this 
study. The three-factor model-2 exhibited well-fitted values compared to the two-factor model. However, the hypothesized two factor model and three factor model-1 also demonstrated marginally acceptable fit indices. In the literature, several interpretations were observed for the inclusion or exclusion of item 'sleep' in factor models. Cleeland et al. [24] have suggested that the item 'sleep' would be closely related to the activity interference, while Klepstad et al. [16] and Atkinson et al. [45] proposed that 'sleep' be part of affective interference. Saxena et al. [46] recommend the sleep item be removed from the instrument. Zeng and Wu et al. [42, 43] have removed the item sleep from the instrument. Disturbed 'sleep' is one of the main complaints made by the patients with cancer pain. The studies have shown that sleep disturbances contributed to increased pain or pain interfered with sleep [47]. Further, it has been suggested that sleep disturbances in chronic pain patients may increase pain sensitivity and create a self-perpetuating cycle of sleep disruption and increased pain [48]. As authors, we strongly believe that the interference to sleep item should be assessed among patients with cancer pain, irrespective of the factor model it belongs to. Comparison of the factor models of the original study and other studies identified in literature was illustrated in Table 6.

Findings of this study support the use of either the twofactor or three-factor model-2 for scoring the SF BPI-Sin. Our observations are comparable with a number of previous studies in which the two factor model (severity and interference) of the SF BPI $(27,41)$. In populations where a differentiation between activity and affective interference is not appropriate or practicable, the two-factor structure can be used. However, when an additional distinction is required between activity and affective interference, the three-factor model- 2 would be realistic and acceptable for use.

The present study has a few limitations. Firstly, we have not evaluated the SF BPI-Sin's test-retest reliability and responsiveness. As a patient reported outcome instrument, SF BPI-Sin needs to achieve the standards of validity and reliability. Among reliability analyses, one of the most important measure is the test-retest reliability; which is a measure of the reproducibility of the scale and the ability to provide consistent scores over time in a stable population. A basic concept with regard to testretest reliability is the need to re-test among clinically stable patients [49]. This situation is particularly challenging when it comes to patients with cancer, because of their faster clinical deterioration. The retest of a clinically unstable patient may incorrectly define the tool as a nonreliable tool. However, we believe that the translated tool would be useful in comprehensive assessment of severity and interference of cancer pain and, in monitoring the response to pain interventions. Secondly, few previous studies discuss on the relationship between severity of pain with the type, stage of cancer and the type of treatment intervention [50]. Although, the present study population was not limited to a specific type of cancers, further studies are recommended using patients with different types of cancers, to check conformity with our results. Further, it would have been ideal if the concurrent validity was assessed at the time of conducting this study using a gold standard instrument to measure cancer pain.

\section{Conclusions}

We conclude that SF BPI-Sin is a statistically confirmed, valid and reliable tool that can be used to assess the intensity of cancer pain and its interference with the functions of the Sinhala speaking population in Sri Lanka during the routine clinical practice and in clinical research.

\section{Abbreviations}

SF BPI-Sin: Short form Brief Pain Inventory - Sinhala version; CFA: Confirmatory Factor Analysis; RMSEA: Root Mean Square Error of Approximation; GFI: Goodness of Fit Index; AGFI: Adjusted Goodness of Fit Index; SRMR: Standardized Root Mean Square Residual; CFI: Comparative Fit Index; NNFI: Non-Normed Fit Index; PGFI: Parsimony Goodness of Fit Index; PNFI: Parsimonious Normed Fit Index; HTMT: Heterotrait-Monotrait criterion; AVE: Average Variance Extracted; CR: Composite Reliability.

Table 6 Factor models of SF BPI in original study and other studies

\begin{tabular}{|c|c|c|c|c|c|c|c|c|c|}
\hline \multirow[t]{2}{*}{ Factors } & \multicolumn{3}{|l|}{ Two factors } & \multicolumn{3}{|c|}{ Three factors without item 'sleep' } & \multicolumn{2}{|c|}{ Three factor-1 } & \multirow{2}{*}{$\begin{array}{l}\text { Three } \\
\text { factor-2 } \\
\text { Cleeland } \\
\text { et al. [24] }\end{array}$} \\
\hline & $\begin{array}{l}\text { Original } \\
\text { study [11] }\end{array}$ & $\begin{array}{l}\text { Aisyaturridha } \\
\text { et al. [41] }\end{array}$ & $\begin{array}{l}\text { Ger et al. } \\
{[21]}\end{array}$ & $\begin{array}{l}\text { Saxena et al. } \\
{[46]}\end{array}$ & $\begin{array}{l}\text { Zeng et al. } \\
\text { [43] }\end{array}$ & $\begin{array}{l}\text { Wu et al. } \\
{[42]}\end{array}$ & $\begin{array}{l}\text { Klepstad } \\
\text { et al. [17] }\end{array}$ & $\begin{array}{l}\text { Atkinson } \\
\text { et al. [45] }\end{array}$ & \\
\hline Severity & WLAN & WLAN & WLAN & WLAN & WLAN & WLAN & WLAN & WLAN & WLAN \\
\hline Activity & \multirow{2}{*}{$\begin{array}{l}\text { WAW, sleep, } \\
\text { REM }\end{array}$} & \multirow{2}{*}{$\begin{array}{l}\text { WAW, sleep, } \\
\text { REM }\end{array}$} & \multirow{2}{*}{$\begin{array}{l}\text { WAW, sleep, } \\
\text { REM }\end{array}$} & WAW & WAW & WAW & WAW & WAW & WAW, sleep \\
\hline Affective & & & & REM & REM & REM & REM, sleep & REM, sleep & REM \\
\hline
\end{tabular}

WLAN — the pain severity items ( W - worst, L-least, A-average, $\mathrm{N}$-now)

REM - the affective cluster of interference items ( $R$ - relations with others, $E$-enjoyment of life and $M$ - mood),

WAW - the activity cluster of interference items (W-walking, A-general activity and W-work) 


\section{Acknowledgements}

The authors, with great respect, appreciate the cooperation extended by the staff of Pain Clinic, Apeksha Hospital, Maharagama, Sri Lanka and all the study participants. We wish to acknowledge with appreciation the assistance, coordination and guidance given by Dr. Tito Mendoza, MD Anderson Research Center, USA and Ms. Yamuna Athukorala, (Lecturer-Probationary), Dr. Saman Nanayakkara (Senior Lecturer in Oral and Maxillofacial Surgery), Prof. Ranjith Pallegama (Professor in Physiology) and Prof. AM Attygalla (Professor in Oral and Maxillofacial Surgery) from the University of Peradeniya, Sri Lanka for their contribution in the translation and harmonization process of SF BPI-Sin.

\section{Authors' contributions}

TRM, TDA and CSEG made a substantial contribution to the concept and design of the work and revised the article and approved the version to be published. NPE carried out the research study, analyzed and interpreted the data and drafted the article. All authors have read and approved the final manuscript.

\section{Funding}

The study was funded by the Cancer Research Center, Faculty of Medical Sciences, University of Sri Jayewardenepura, Sri Lanka. (Grant No: 002/2017). The funding body has no role in the design of the study and collection, analysis, and interpretation of data and in writing the manuscript.

\section{Availability of data and materials}

The data utilized to support the findings of this study are available from the corresponding author upon reasonable request.

\section{Ethics approval and consent to participate}

The Ethics Review Committee of the Faculty of Medical Sciences, University of Sri Jayewardenepura, Sri Lanka (ERC no:32/17) has approved the study. All participants provided informed written consent to participate.

\section{Consent for publication}

Not applicable.

\section{Competing interests}

The authors declare that they have no competing interests.

\section{Author details}

${ }^{1}$ Faculty of Graduates Studies, University of Sri Jayewardenepura, Nugegoda, Sri Lanka. ${ }^{2}$ Department of Clinical Sciences, General Sir John Kotelawala Defence University, Ratmalana, Sri Lanka. ${ }^{3}$ Department of Nursing and Midwifery, Faculty of Allied Health Sciences, University of Sri Jayewardenepura, Nugegoda, Sri Lanka. ${ }^{4}$ Department of Community Medicine, Faculty of Medical Sciences, University of Sri Jayewardenepura, Gangodawila, Nugegoda, Sri Lanka. ${ }^{5}$ Cancer Research Centre, Faculty of Medical Sciences, University of Sri Jayewardenepura, Nugegoda, Sri Lanka.

Received: 5 July 2020 Accepted: 12 February 2021

Published online: 23 February 2021

\section{References}

1. Kwon JH, Hui D, Chisholm G, Hong WT, Nguyen L, Bruera E. Experience of barriers to pain management in patients receiving outpatient palliative care. J Palliat Med. 2013;16(8):908-14. https://doi.org/10.1089/ jpm.2012.0610.

2. Amasha RR, Christo PJ (n.d.) Cancer pain: etiology, barriers, assessment, and treatment. Pain Report, 14. https://cme.dannemiller.com/articles/ activity?id=416\&f=1. Accessed 03 March 2020

3. van den Beuken-van Everdingen $M$, de Rijke J, Kessels A, Schouten $H$, van Kleef M, Patijn J. Prevalence of pain in patients with cancer: a systematic review of the past 40 years. Ann Oncol. 2007;18(9):1437-49. https://doi. org/10.1093/annonc/mdm056.

4. Oliver DP, Wittenberg-Lyles E, Demiris G, Washington K, Porock D, Day M. Barriers to pain management: caregiver perceptions and pain talk by hospice interdisciplinary teams. J Pain Symptom Manage. 2008;36(4):374-82. https://doi.org/10.1016/j.jpainsymman.2007.11.005.
5. Otis-Green S, Sherman R, Perez M, Baird RP. An integrated psychosocial-spiritual model for cancer pain management. Cancer Pract. 2002;10(s1):s58-65. https://doi.org/10.1046/j.1523-5394.10.s.1.13.x.

6. Gureje O, Von Korff M, Simon GE, Gater R. Persistent pain and wellbeing: a World Health Organization study in primary care. JAMA. 1998;280(2):147-51. https://doi.org/10.1001/jama.280.2.147.

7. Caraceni A, Cherny N, Fainsinger S, et al. Pain measurement tools and methods in clinical research in palliative care: recommendations of an Expert Working Group of the European Association of Palliative Care. J Pain Symptom Manag. 2002;23(3):239-55.

8. Melzack R, Casey KL. Sensory, motivational, and central control determinants of pain: a new conceptual model. In: Kenshalo D, editor. International symposium on the skin senses, Chapter 20. Springfield: C.C. Thomas; 1968. p. 423-35.

9. PDQ Supportive and Palliative Care Editorial Board. Cancer Pain $\left(\mathrm{PDQ}^{\circledR}\right)$ : Health Professional Version. 2019 Oct 30. In: PDQ Cancer Information Summaries [Internet]. Bethesda (MD): National Cancer Institute (US); 2002. https://www.ncbi.n/m.nih.gov/books/NBK65949/

10. Anderson KO, Mendoza TR, Payne R, Valero V, Palos GR, Nazario A, Richman SP, Hurley J, Gning I, Lynch GR, Kalish D, Cleeland CS. Pain education for underserved minority cancer patients: a randomized controlled trial. J Clin Oncol. 2004;22(24):4918-25. https://doi.org/10.1200/ JCO.2004.06.115.

11. Cleeland CS. Measurement of pain by subjective report. In: Chapman CR, Loeser JD, editors. Issues in pain measurement. Advances in pain research and therapy, vol. 12. New York: Raven Press; 1989. p. 391-403.

12. MD Anderson Cancer Center, Sample of Short form Brief pain inventory. https://www.mdanderson.org/documents/Departments-and-Divisions/ Symptom-Research/BPI-SF_English-24h_Original_SAMPLE.pdf

13. Charles S. Cleeland. The Brief Pain Inventory User Guide, 1991. https:// www.mdanderson.org/documents/Departments-and-Divisions/Sympt om-Research/BPI_UserGuide.pdf

14. Ferreira KA, Teixeira MJ, Mendonza TR, Cleeland CS. Validation of brief pain inventory to Brazilian patients with pain. Support Care Cancer. 2011;19(4):505-11. https://doi.org/10.1007/s00520-010-0844-7.

15. Dworkin RH, Turk DC, Farrar JT, Haythornthwaite JA, Jensen MP, Katz NP, Kerns RD, Stucki G, Allen RR, Bellamy N, Carr DB, Chandler J, Cowan P, Dionne R, Galer BS, Hertz S, Jadad AR, Kramer LD, Manning DC, et al. Core outcome measures for chronic pain clinical trials: IMMPACT recommendations. Pain. 2005;113(1):9-19. https://doi.org/10.1016/j. pain.2004.09.012.

16. Celik EC, Yalcinkaya EY, Atamaz F, Karatas M, Ones K, Sezer T, et al. Validity and reliability of a Turkish Brief Pain Inventory Short Form when used to evaluate musculoskeletal pain. J Back Musculoskel Rehabil. 2017;30(2):229-33. https://doi.org/10.3233/BMR-160738.

17. Klepstad P, Loge JH, Borchgrevink PC, Mendoza TR, Cleeland CS, Kaasa S. The Norwegian Brief Pain Inventory Questionnaire: translation and validation in cancer pain patients. J Pain Symptom Manage. 2002;24(5):517-25.

18. Chaudakshetrin P. Validation of the Thai Version of Brief Pain Inventory (BPI-T) in cancer patients. J Med Assoc Thailand. 2009;92(34-40):407-16.

19. Wang XS, Mendoza TR, Gao S-Z, Cleeland CS. The Chinese version of the Brief Pain Inventory (BPI-C): its development and use in a study of cancer pain. Pain. 1996:67:2-3.

20. Mystakidou K, Mendoza T, Tsilika E, et al. Greek brief pain inventory: validation and utility in cancer pain. Oncology. 2001;60(1):35-42.

21. Ger L-P, Ho S-T, Sun W-Z, Wang M-S, Cleeland CS. Validation of the Brief Pain Inventory in a Taiwanese population. J Pain Symptom Manag. 1999;18(5):316-22.

22. Kalyadina SA, Ionova TI, Ivanova MO, Uspenskaya OS, Kishtovich AV, Mendoza TR, et al. Russian brief pain inventory: validation and application in cancer pain. J Pain Symptom Manage. 2008;35(1):95-102. https://doi. org/10.1016/j.jpainsymman.2007.02.042.

23. World Health Organization. Cancer pain relief: with a guide to opioid availability, 2nd ed. World Health Organization, 1996. https://apps.who. int/iris/handle/10665/37896

24. Cleeland CS. Assessment of pain in cancer: measurement issues. In: Foley KM, editor. Advances in pain research and therapy, vol. 16. New York: Raven Press; 1990. p. 47-55.

25. Cleeland CS, Ryan KM. Pain assessment: global use of the Brief Pain Inventory. Ann Acad Med Singapore. 1994;23(2):129-38. 
26. Cleeland CS, Nakamura Y, Mendoza TR, Edwards KR, Douglas J, Serlin RC Dimensions of the impact of cancer pain in a four country sample: new information from multidimensional scaling. Pain. 1996;67(2-3):267-73.

27. Annual health Bulletin, Medical Statistics Unit, Ministry of Health, Nutrition and Indigenous Medicine, Sri Lanka. 2015, ISBN 978-955-702-045-7

28. Edirisinghe NP, Makuloluwa TR, Amarasekara TD, Goonewardena CSE. Psychometric Properties of Sinhala Version of Short-Form McGill Pain Questionnaire-2 (SF MPQ-2-Sin) among Patients with Cancer Pain in Sri Lanka. Pain Res Manag. 2019. https://doi.org/10.1155/2019/5050979.

29. Tabachnick BG, Fidell LS. Using multivariate statistics. 6th ed. New York: Harper Collins; 2005

30. IBM Corp. Released 2011. IBM SPSS Statistics for Windows, Version 20.0. Armonk, NY: IBM Corp.

31. Hair JF, Black WC, Babin BarryJ, Anderson RE. Multivariate data analysis. Eighth edition. Andover, Hampshire: Cengage; 2019

32. Cronbach LJ. Coefficient alpha and the internal structure of tests. Psychometrika. 1951;16(3):297-334.

33. Fornell C, Larcker DF. Evaluating structural equation models with unobservable variables and measurement error. J Mark Res. 1981;18(1):39.

34. Ab Hamid MR, Sami W, Mohmad Sidek MH. Discriminant validity assessment: use of Fornell \& Larcker criterion versus HTMT Criterion. J Phys Conf Ser. 2017;890:012163. https://doi.org/10.1088/1742-6596/890/1/012163.

35. Jöreskog KG, Sörbom D. LISREL 10 for Windows [Computer software]. Skokie, IL: Scientific Software International Inc; 2018.

36. Hu L, Bentler PM. Cutoff criteria for fit indexes in covariance structure analysis: Conventional criteria versus new alternatives. Struct Equ Model Multidiscip J. 1999;6(1):1-55. https://doi.org/10.1080/107055199095401 18.

37. Kaiser H. A second generation little jiffy. Psychometrika. 1970;35(4):401-15.

38. Joreskog KG, Sorbom D. LISREL8: user's reference guide, Scientific Software. Mooresville, NC, USA, 1996.

39. Jackson DL, Gillaspy JA, Purc-Stephenson R. Reporting practices in confirmatory factor analysis: an overview and some recommendations. Psychol Methods. 2009;14(1):6-23. https://doi.org/10.1037/a0014694.

40. Mulaik SA. Parsimony and model evaluation. J Exp Educ. 1998;66(3):266-73.

41. Aisyaturridha A, Naing L, Nizar AJ. Validation of the Malay brief pain inventory questionnaire to measure cancer pain. J Pain Symptom Manag. 2006;31(1):13-21. https://doi.org/10.1016/j.jpainsymman.2005.06.011.
42. Wu JSY, Beaton D, Smith PM, Hagen NA. Patterns of pain and interference in patients with painful bone metastases: a brief pain inventory validation study. J Pain Symptom Manag. 2010;39(2):230-40. https://doi org/10.1016/j.jpainsymman.2009.07.006.

43. Zeng. Analysis of pain and interference patterns with brief pain inventory in patients with bone metastases: a confirmatory study. World J Oncol 2011. https://doi.org/10.4021/wjon322w

44. Nurosis, M. Statistical Data Analysis, SPSS Inc., 1994, Chicago, IL

45. Atkinson TM, Rosenfeld BD, Sit L, Mendoza TR, Fruscione M, Lavene D, Shaw M, LiY, Hay J, Cleeland CS, Scher HI, Breitbart WS, Basch E. Using confirmatory factor analysis to evaluate construct validity of the Brief Pain Inventory (BPI). J Pain Symptom Manag. 2011;41(3):558-65. https://doi. org/10.1016/j.jpainsymman.2010.05.008.

46. Saxena A, Mendoza T, Cleeland CS. The Assessment of Cancer Pain in North India: the validation of the hindi brief pain inventory-BPI-H. J Pain Symptom Manag. 1999;17(1):15.

47. Rumble ME, Keefe FJ, Edinger JD, Porter LS, Garst JL. A pilot study investigating the utility of the cognitive-behavioral model of insomnia in earlystage lung cancer patients. J Pain Symptom Manag. 2005;30(2):160-9. https://doi.org/10.1016/j.jpainsymman.2005.02.013.

48. Sayar K, Arikan M, Yontem T. Sleep quality in chronic pain patients. Can J Psychiatry. 2002;47(9):844-8. https://doi.org/10.1177/070674370204700 905.

49. Fayers P, Machin D. Quality of Life. Assessment, analysis and interpretation. 2nd ed. Chichester: Wiley; 2007.

50. van den Beuken-van Everdingen MHJ, Hochstenbach LMJ, Joosten EAJ, Tjan-Heijnen VCG, Janssen DJA. Update on prevalence of pain in patients with cancer: systematic review and meta-analysis. J Pain Symptom Manag. 2016;51(6):1070-1090.e9. https://doi.org/10.1016/j.jpainsymma n.2015.12.340.

\section{Publisher's Note}

Springer Nature remains neutral with regard to jurisdictional claims in published maps and institutional affiliations.
Ready to submit your research? Choose BMC and benefit from:

- fast, convenient online submission

- thorough peer review by experienced researchers in your field

- rapid publication on acceptance

- support for research data, including large and complex data types

- gold Open Access which fosters wider collaboration and increased citations

- maximum visibility for your research: over $100 \mathrm{M}$ website views per year

At BMC, research is always in progress.

Learn more biomedcentral.com/submissions 